\title{
The comorbidity of bipolar disorder, diabetes mellitus, and autoimmune hypothyroidism in an adult woman with Turner's syndrome: a case report
}

This article was published in the following Dove Press journal:

Neuropsychiatric Disease and Treatment

18 September 2017

Number of times this article has been viewed

\section{Jinling Li \\ Xiaohong Hong \\ Haiyun Xu}

The Mental Health Center, Shantou University Medical College, Shantou, Guangdong, People's Republic of China
Correspondence: Haiyun Xu The Mental Health Center, Shantou University Medical College, 22\# Xinling Road, Shantou 5I504I, Guangdong, People's Republic of China Tel +867548890 0728 Email hyxu@stu.edu.cn
Abstract: Turner's syndrome (TS) is the most common sex chromosome abnormality in females and characterized with short stature and ovarian dysgenesis. Patients with TS may also present many other physical diseases and mental disorders. In this case report, we present a 49 -year-old woman with TS, who also met criteria for bipolar disorder, type 2 diabetes mellitus, and autoimmune hypothyroidism. The patient was admitted to the mental health center for depressive symptoms in 1991 and was misdiagnosed as hypopituitarism, which was not corrected until 2005 when her karyotype of 45, X/46, X, i Xq) was identified. Due to the misdiagnosis and other specific reasons, the patient missed the optimal time for hormone replacement therapy.

Keywords: Turner's syndrome, bipolar disorder, karyotype, comorbidity

\section{Introduction}

Turner's syndrome (TS) is the most common sex chromosome abnormality in females, affecting approximately 1/3,000 live-born infants. ${ }^{1}$ Of females diagnosed with $\mathrm{TS}$, about half are monosomic for the X chromosome (karyotype 45, X). Among the rest, the most frequent are the mosaic karyotypes of 45, X/46, XX; 45, X/46, X, i(Xq); and $45, \mathrm{X} / 46, \mathrm{XY}^{2}$ The most common physical features of TS are short stature and ovarian dysgenesis with subsequent infertility. Other symptoms may include cardiac and renal malformations, skeletal anomalies such as missing fourth or fifth metacarpal bone, narrow and high-arched palate, micrognathia, shield-like chest, cubitus valgus, pterygium colli (redundant skinfold on the back of the neck), a fish-like mouth, hypoplastic and widely spaced nipples, multiple pigmented nevi, low posterior hairline, hypoplastic nails of hands and feet, and a tendency to otitis media which untreated may lead to a perceptive hearing loss. ${ }^{3-5}$ In addition, girls and women with TS demonstrate a distinct neurocognitive profile where visual-spatial abilities, working memory, and executive function may be impaired, ${ }^{6-9}$ although verbal ability is generally normal. ${ }^{10-12}$ Moreover, a number of case reports described the association of TS with affective, schizoaffective, and schizophrenic psychoses. ${ }^{13-15}$ In this case report, we present an adult woman with TS, who was also diagnosed with bipolar disorder (BD), type 2 diabetes mellitus, and autoimmune hypothyroidism.

\section{Case report}

The patient was a 49-year-old Chinese female living in Shantou, China. Accompanied by her elder brother, she came (in March 2016) to the outpatient department of the Mental Health Center, Shantou University Medical College, for excessive talking, 
nosiness, rash spending, decreased need for sleep, and irritable mood that had persisted for 3 weeks.

The patient was $138 \mathrm{~cm}$ tall and had been diagnosed with TS, confirmed by the karyotype of 45, X/46, X, i(Xq). Physical findings included the following: short neck, multiple pigmented nevi over face, moderate hearing impairment in both ears, small breasts, flat nipples, and thin flat vulva, as well as sparse armpit and pubic hairs. The other systemic examinations were as follows: weight of $40 \mathrm{~kg}$ and blood pressure of 97/70 mmHg. Electrocardiogram showed inverted T waves in leads V3-V6, while electroencephalogram and magnetic resonance imaging of the brain seemed to be normal. Ultrasonography showed small ovaries and uterus, as well as smaller right kidney. Moreover, ultrasonography revealed diffuse hyperplasia in the thyroid glands although no abnormal blood flow signal was seen.

During the physical examination, the patient showed clear consciousness and good eye contact while talked about irrelevant issues, although she did demonstrate inattention by looking elsewhere during the interaction. The full-scale Wechsler IQ (Chinese version) score was 66, with performance IQ score of 73 and verbal IQ score of 75.

Laboratory findings included the following: decreased levels of estradiol (19 ng/L), progesterone $(0.3 \mu \mathrm{g} / \mathrm{L})$, and serum testosterone $(0.07 \mu \mathrm{g} / \mathrm{L})$ and normal levels of folliclestimulating hormone (FSH; $69.8 \mathrm{IU} / \mathrm{L})$, luteinizing hormone (LH; $14.1 \mathrm{IU} / \mathrm{L})$, and cortisol (10.4 $\mu \mathrm{g} / \mathrm{dL})$. Her fasting blood sugar $(8.5 \mathrm{mM} / \mathrm{L})$ and glycosylated hemoglobin (7.5\%) were higher although serum insulin (12.8 IU/mL) levels were within normal range. In addition, her total thyroxine (TT4; $66.6 \mu \mathrm{g} / \mathrm{L}$ ) and total triiodothyronine (TT3; $0.9 \mathrm{ng} / \mathrm{mL}$ ) were lower, while thyroid-stimulating hormone (TSH; $7.9 \mathrm{IU} / \mathrm{mL}$ ) was higher along with high levels of autoantibody to thyroid peroxidase (TPO; $180 \mathrm{U} / \mathrm{mL}$ ).

The patient had a full-term vaginal birth. Her mother took medicaments to attempt to abort the pregnancy. She was the youngest child of a lower class family with eight children. Of her seven siblings (four brothers and three sisters), two brothers had history of mood disorders, which had been successfully treated.

She developed slowly during childhood and was shorter compared to her peers of the same age. She had significant academic difficulties, did not finish primary education, and never had a job. She did not experience the onset of menstruation after puberty. She married when she was 32 years old, but never had children.

Because of amenorrhea and short stature, she gradually became depressed and self-blamed, had no self-confidence, and believed she was useless. She isolated herself at home and hesitated to meet others. She had poor appetite and sleep and tried to suicide. Because of these problems and symptoms, she was admitted to the mental health center in 1991. She was diagnosed with depression and secondary hypopituitarism and treated with doxepin, which did significantly improve her symptoms.

In November 1992, the patient was admitted to the center again for depressive mood and suspicion of others. She suspected that her home had been stolen by one of her sistersin-law and showed lack of impulse control and loss of temper. She was diagnosed with depression and depression-induced psychotic disorder. After perphenazine (16 mg/day) and doxepin (100 mg/day) treatments, her symptoms improved, and she was discharged from the center. At home, she kept up with taking her medication.

In 1995, after the discontinuation of the medication, she was admitted to the center a third time for excessive talking, hyperactivity, buying things for others without reason, and excessive praying. At home, she had difficulty controlling herself and would have outbursts with shouting and crying and other disruptive behavior. She was diagnosed with affective disorder with manic episodes, pulmonary tuberculosis, which was shown in a chest X-ray, and hypopituitarism. Her symptoms improved after treatment with antituberculosis drugs and clozapine, after which, she was discharged from the center.

The patient was hospitalized in both 2001 and 2004, for the same manic episodes including excessive talking, hyperactivity, rash spending, and difficulty controlling herself.

In 2005, the patient became depressed and stupefied, slow in her movements, lazy, and maintained erratic hours. During hospitalization, a karyotypic analysis was performed and the karyotype of $45, \mathrm{X} / 46, \mathrm{X}, \mathrm{i}(\mathrm{Xq})$ was identified which led to the diagnosis of TS. An endocrinologist initiated estrogen and progestin replacement therapy, and sodium valproate (1.0 g/day) was also prescribed. The patient's mood stabilized, and she was discharged from the center; however, she did not continue the estrogen and progestin replacement therapy. Menses was present during the second cycle of treatment.

In 2009, the patient was hospitalized again for a manic episode. During hospitalization, her fasting blood sugar was found to be high, leading to a diagnosis of diabetes mellitus for which metformin was prescribed, in addition to sodium valproate for the manic symptoms.

It was concluded that the previous diagnosis of hypopituitarism was incorrect as there was no laboratory evidence 
to support this diagnosis. Unfortunately, the misdiagnosis had not been corrected until 2005 when a karyotype of $45, \mathrm{X} / 46, \mathrm{X}, \mathrm{i}(\mathrm{Xq})$ was identified. It is likely that the psychiatric practitioner was not knowledgeable regarding TS and hypopituitarism.

\section{Discussion}

This is a very special case of TS as the patient also met the criteria for $\mathrm{BD}$, type 2 diabetes mellitus, and autoimmune hypothyroidism. This is the first TS case reported in China with multiple medical comorbidities of the abovementioned conditions. Of the previous clinical studies of TS in China, one case report described depressive symptoms in an adult woman with TS. ${ }^{16}$ Another study analyzed 17 patients with TS with psychological abnormalities including schizophrenialike symptoms in 14 of the patients and manic symptoms in the remaining three. ${ }^{17}$ Another three case reports described psychotic symptoms in adult females with TS. ${ }^{18-20}$ No report, however, has been published in a Chinese journal describing BD symptoms in patients with TS. According to this finding, there were only three reports available in English journals describing manic-depressive symptoms associated with TS. ${ }^{14,15,21}$ Interestingly, the cases reported in English journals, and the current case also showed a mosaic chromosome pattern of $45, \mathrm{X} / 46, \mathrm{XX}$ (including $\mathrm{X}, \mathrm{i}[\mathrm{Xq}]$ and $\mathrm{X}, \mathrm{r}[\mathrm{X}]$ ).

The patient in the current report was 49 years old when she was admitted to the mental health center for the last time. The long course of TS may be a risk factor for developing the physical diseases she suffered from. In line with this interpretation, a recent case report demonstrated symptoms of diabetes and subclinical hypothyroidism in a 52-year-old woman with TS. $^{22}$ However, the comorbidity of TS and autoimmune thyroid diseases (AITDs) was also seen in young patients. $^{23,24}$ Instead of the long course of TS, the karyotype of patients may be a risk factor for AITD as evidenced by a recent study reporting that $38.6 \%$ (17/44) of patients with TS were diagnosed as having AITD. More significantly, 75\% (9/12) of patients with TS with karyotype of $45, \mathrm{X} / 46, \mathrm{X}$, $\mathrm{i}(\mathrm{Xq})$, or $45, \mathrm{X} / 46, \mathrm{X}, \mathrm{i}(\mathrm{Xp})$ were diagnosed with AITD, of whom $58.3 \%$ were diagnosed with hypothyroidism. ${ }^{25}$ In the current case, the patient with TS was also diagnosed with autoimmune hypothyroidism as evidenced by lower levels of TT4 and TT3 and higher levels of TSH along with high levels of autoantibody to TPO.

As previously mentioned, the patient was misdiagnosed with hypopituitarism which was not corrected until 2005 when a karyotype of 45, X/46, X, i(Xq) was identified. This might be mainly due to the lack of knowledge about TS of some pediatricians and psychiatrists in China. Unfortunately, this was not the only case in China. A similar misdiagnosis was reported recently in which a 20-year-old woman with TS was diagnosed with hypopituitarism before the identification of her karyotype of 45, X. The patient also met the criteria for diabetes mellitus. ${ }^{26}$ Moreover, another recent study reported the diagnoses of 10 patients with TS, of whom four were misdiagnosed with Hashimoto's thyroiditis because of hypothyroidism symptoms, one was misdiagnosed with Graves' disease because of hyperthyroidism, one was misdiagnosed with hypophysoma, one was misdiagnosed with idiopathic scoliosis, and the other one was misdiagnosed with chronic otitis media and subjected to surgical treatments with discouraging effects. ${ }^{27}$

The misdiagnosis of a patient with TS often results in missing the optimal time for growth hormone substitution. The patient reported in this case report, however, was a very special case due to the following two conditions. First, growth hormone substitution was unavailable during the 1970s and hardly available during the 1980s in China. Second, the family of the patient having eight children and being low income was unlikely able to afford the relatively costly hormone replacement therapy. Both of these factors played a role in the patient's unwillingness to continue the estrogen and progestin replacement therapy.

The patient agreed to the publication of this case report and signed a written informed consent before we prepared this manuscript.

\section{Disclosure}

The authors report no conflicts of interest in this work.

\section{References}

1. Nielson J, Wohlet TM. Chromosome abnormalities found among 34910 newborn children: results from a 13-year incidence study in Arhus, Denmark. Hum Genet. 1991;87(1):81-83.

2. Sybert VP. Phenotypic effects of mosaicism for $147, \mathrm{XXX}$ cell line in Turner syndrome. J Med Genet. 2002;39(3):217-221.

3. Kron L, Gorzynski G, Weiner H. Anorexia nervosa and gonadal dysgenesis. Arch Gen Psychiatry. 1977;34(3):332-335.

4. Propping P. Psychiatrische Genetik: Befunde und Konzepte. Berlin: Springer; 1989.

5. Schwanitz G, Tietze HU, Zerres K, Schaaf A. Gonadendysgenesie: Variationsbreite klinischer, hormoneller, zytogenetischer und histologischer Befunde. Klin Padiatr. 1983;195:422-429.

6. Downey J, Elkin EJ, Erhardt AA, Meyer-Bahlburg HF, Bell JJ, Morishima A. Cognitive ability and everyday functioning in women with Turner syndrome. J Learn Disabil. 1991;24(1):32-39.

7. Money J. Specific neuro-cognitive impairments associated with Turner's (45 XO) and Klinefelter (47 XXY) syndromes: a review. Sociobiology. 1993;40(1-2):147-151.

8. Nijhuis-van der Sanden MWG, Van Asseldonk EHF, Eling PATM, Van Galen GP. Slow motor performance in girls with Turner syndrome is not related to increased neuromotor noise. Motor Control. 2003;7(2):111-133. 
9. Siegel PT, Clopper R, Stabler B. The psychological consequences of Turner syndrome and review of the National Cooperative Growth Study Psychological Sub-study. Pediatrics. 1998;102:488-491.

10. Ratcliffe SG, Butler GE, Jones M. Edinburgh study of growth and development of children with sex chromosome abnormalities. IV. Birth Defects Orig Artic Ser. 1990;26(4):1-44.

11. Rovet JF. The psychoeducational characteristics of children with Turner syndrome. J Learn Disabil. 1993;26(5):333-341.

12. Temple CM, Carney R. Reading skills in children with Turner's syndrome: an analysis of hyperplexia. Cortex. 1996;32(2):335-345.

13. Cardoso G, Daly RJ, Haq NA, et al. Current and lifetime psychiatric illness in women with Turner syndrome. Gynecol Endocrinol. 2004; 19(6):313-319.

14. Quaranta G, Maremmani AG, Perugi G. Anti-AMPA-receptor encephalitis presenting as a rapid-cycling bipolar disorder in a young woman with Turner syndrome. Case Rep Psychiatry. 2015;2015:273192.

15. Anam S, Jummani R, Coffey B, Wieland N. Treatment of juvenile-onset bipolar disorder in a child with Turner's syndrome. J Child Adolesc Psychopharmacol. 2007;17(3):384-390.

16. Shen JH. Depression-like symptoms in a patient with Turner's syndrome. Sichuan Mental Health. 1999;12:106.

17. Feng ZY, Tian HJ, Liu JX. Manic-depressive or schizophrenia like symptoms in patients with Turner's syndrome. Chin J Birth Health Heredity. 1998;6:58-61.
18. Ma JQ, Feng ZY. Psychotic symptoms in a Turner's syndrome mosaicism of 45, X/46, X, i(Xq)/46, XX. Chin J Psychiatry. 2000;33:256.

19. Liu XL, Li WX. Psychotic symptoms in two patients with Turner's syndrome. Chin J Med Genet. 2001;18:263.

20. Deng L. Psychotic symptoms associated with Turner's syndrome: a case report. Med J Chin People Health. 2014;26:130.

21. Fishbain DA, Vilasuso A. Manic-depressive illness associated with Turner's syndrome mosaicism. J Nerv Ment Dis. 1981;169(7): 459-461.

22. Chen L, Jing XH. Diabetes and subclinical hypothyroidism in a patient with Turner's syndrome. J Clin Interm Med. 2015;32:844-845.

23. Zhang M, Shun B, Meng B, Chen ZY. Hyperthyroidism associated with Hashimoto's thyroiditis in patients with Turner's syndrome. Chin $J$ Birth Health Heredity. 2013;21:55.

24. Liu H, Liu GL. Autoimmune thyroid disease associated with Turner's syndrome mosaicism of 46, X, Xq. Nalt Med J China. 2010;90:3310.

25. Li L, Huang YH, Liu M, Jing Q, Qi XJ, Li J. The association of autoimmune thyroid diseases with karyotypes in patients with Turner's syndrome. China Prac Med. 2011;6:113-115.

26. Hu WL, Zhao SS, Li XF. A misdiagnosis of Turner's syndrome with diabetes mellitus: a case report. Clin Misdiagn Misther. 2011;24:58.

27. Bai G, Peng H, Zeng XW. Analysis of misdiagnosis of 10 patients with Turner's syndrome. Chin J Health Lab Tech. 2010;20(1820):1833.
Neuropsychiatric Disease and Treatment

\section{Publish your work in this journal}

Neuropsychiatric Disease and Treatment is an international, peerreviewed journal of clinical therapeutics and pharmacology focusing on concise rapid reporting of clinical or pre-clinical studies on a range of neuropsychiatric and neurological disorders. This journal is indexed on PubMed Central, the 'PsycINFO' database and CAS,

\section{Dovepress}

and is the official journal of The International Neuropsychiatric Association (INA). The manuscript management system is completely online and includes a very quick and fair peer-review system, which is all easy to use. Visit http://www.dovepress.com/testimonials.php to read real quotes from published authors. 